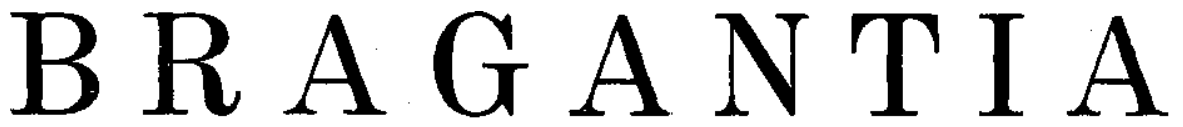

Boletim Técnico do Instituto Agronômico do Estado de São Paulo

Vol. 17

Campinas, novembro de 1958

N.0 4

\title{
VARIEDADES DE CANA-DE-AÇÚCAR
}

\section{II - SERIE DE ENSAIOS REALIZADOS \\ NO PERIODO 1953-1956 $\left(^{*}\right)$}

A. L. Segalla E R. Alvarez, engenheiros-agrônomos, Seçião de Cana-de-Açúcar, Instituto Agronômico

\section{RESUMO}

No presente trabolho sõo apresentados os resultados obtidos em seis ensaios regionais de variedades de cana-de-oçúcar, realizados de 1953 a 1956, nas usinas Santa Elisa, Tamôio, Pôrto Feliz, Itaiquara, Santa Bárbara e Monte Alegre. A finalidade foi determinar, dentre as variedades estudadas as mais recomendáveis para os diversos tipos de solo, nas diferentes regiōes canavieiras do Estado de São Paulo.

Foram estudadas 16 variedades. Em cada ensaio foram feitos três cortes (conaplanta, soca e ressoca), sendo estudados, estatisticamente, os resultados da produção de cana e de açúcar provável do primeiro corte e do total dos três cortes.

Os resultados obtictos mostraram gue a Co. 290 nāo mais deve ser cultivada no Estado de Sāo Paulo. A CB. 40/13 apresentou a maior riqueza em açúcar, sendo a de moturação mais precoce, enquanto a CB. 38/30 apresentou baixa riqueza em açúcar. São recomendados para tôdas as regiōes do Estado as variedades $C B$. 40/69, CB. 41/76 e Co. 419; a CB. 40/13, apesar de sua produtividade e riqueza em açúcar, devido à sua grande sucetibilidade ao mosaico só pode ser cultivada com cuidados especiais. Também sāo recomendadas, porém para determinadas regiões, as variedades: CB. 40/19, CB. $38 / 22$ e CB. 41/70. Outras variedades podem ser cultivadas com piores resultados, em algumas regiōes. Năo devem ser cultivadas no Estado as variedades $\mathrm{N}$ : Co. 352 , CB. $41 / 35$ e CB. $38 / 30$, esta pela baixa riqueza em açúcar que apresenta.

\section{1 - INTRODUÇÃO}

A cultura da cana-de-açúcar já há alguns anos vem ocupando lugar de grande destaque na agricultura brasileira. Atualmente o Brasil ocupa o segundo lugar, entre os produtores de açúcar turbina-

(*) Os autores expressam seus agradecimentos aos engs.-agrs. Hermano Vaz de Arruda, do Seçāo de Técnica Experimental do Instituto Agronômico, pela colaboração prestada nc planejamento; José Pio Nery, da Seção de Tecnologia Agrícola do Instituto Agronômico, pelas análises do caldo: Antonio Carlos Penteado, da Usina Tamóio, Roland Fauconnier da Usina Pôrto Feliz, Eno de Miranda Cardoso e Hércio de Oliveira, da Usina Monte Alegre, e aos srs. Arnaldo Bonini, da Usina Santa Elisa, Silvio Lima Dias, da Usina Itáquara e d̀ odministraçäo da Usina Santa Bárbara, pelá colaboração prestada na execuçóo dos ensaios.

Recebido paro publicaçōo em 7 de novembro de 1957. 
do de cana do mundo. Se compararmos a produção brasileira de $1955 \mathrm{com}$ a média do qüinqüênio 1935-39, verifica-se que houve um aumento de $193,4 \%$. Êste grande aumento deve-se principalmente ao notável desenvolvimento havido no Estado de São Paulo, que é atualmente o maior produtor de açúcar do Brasil, tendo atingido na última safra (1956-57) uma produção de 13082762 sacos de 60 quilos, além de 96383136 litros de álcool ( ${ }^{(1)}$.

$E^{\prime}$ sabido que dentre os fatôres que influem no rendimento de uma cultura, a variedade é dos mais importantes. Na década de 1940-50 a Co. 290 tornou-se a variedade mais cultivada no Estado, ocupando cêrca de $80 \%$ de sua área canavieira, havendo usinas de açúcar que a cultivaram quase com exclusividade. Posteriormente, já no fim dêsse decênio, outras variedades passaram a ser também cultivadas, entre elas as Co. 413 , Co. 421, CP. 34/120, Co. 331 e mais recentemente a Co. 419 , além de outras variedades em menor escala, continuando porém a Co. 290 a predominar. Dessas citadas, a CP. $34 / 120$ e a Co. 331, também conhecida como Co. $3 \mathrm{X}$, tiveram seu plantio proibido, pela sucetibilidade que apresentavam ao carvão da cana, que apareceu por volta de 1946, na região de Assis. Nos últimos anos grande tem sido o número de variedades introduzidas no Estado de São Paulo, provenientes da Estação Experimental de Campos, no Estado do Rio de Janeiro. Algumas dessas variedades estão sendo cultivadas atualmente em escala apreciável. Resultados sôbre algumas dessas variedades já foram apresentados pelos autores (3). Enquanto isso, a Co. 290 vem decaindo de produção, de tal modo a estar sendo abandonado o seu cultivo.

Em continuação ao programa de trabalho com variedades, a Seção de Cana de Açúcar instalou, em princípios de 1953, uma série de oito ensaios, localizados nas principais zonas canavieiras do Estado. Nesses ensaios foram estudadas as variedades " $\mathrm{CB}$ " mais promissoras, introduzidas até aquela ocasião, comparando-as com as variedades Co. 290, $413,419,421$ e CB. 36/14, consideradas como as mais recomendáveis para o Estado, em trabalho anterior (2).

Foram instalados oito ensaios; um dêles ( $n .^{\circ} 47$ ), localizado em terra-roxa-misturada do glacial, na Usina Ester, município de Cosmópolis, foi abandonado devido à péssima germinação apresentada. De outro ( $n .^{\circ} 45$ ), localizado no arenito de Bauru, na Usina Miranda, mu-

(1) Dados oficiais do Instituto do Açúcar e do Álcool. 
nicípio de Pirajuí, perdeu-se o primeiro corte. Não figuram neste trabalho os resultados obtidos no segundo e terceiro cortes dêste ensaio, por apresentarem valor muito restrito sem os resultados do primeiro corte.

O objetivo do presente trabaiho é relatar os resultados obtidos nessa segunda série de ensaios, efetuados em continuação aos estudos sôbre variedades de cana-de-açúcar (2).

\section{2 - MATERIAL E MÉTODO}

Para instalação dos ensaios foram escolhidas, como já foi dito, usinas situadas nas principais zonas canavieiras do Estado, abrangendo os diversos tipos de solo cultivados com a cana-de-açúcar. Assim, os ensaios n. ${ }^{\circ} 42,43$ e 49 foram localizados em terra-roxa-misturada, sendo o primeiro na Usina Santa Elisa, no município de Sertãozinho, o segundo na Usina Tamôio, município de Araraquara e o terceiro na Usina Monte Alegre, município de Piracicaba; o de $n .^{\circ} 44$ foi localizado também em terra-roxa-misturada, porém do glacial, na Usina Pôrto Feliz, no município do mesmo nome; o de n. ${ }^{\circ} 46$, em massapêsalmouräo, da Usina Itaiquara, município de Tapiratiba e o de $n$. $^{\circ}$ 48, na Usina Santa Bárbara no município de Santa Bárbara Do Oeste, em terra arenosa do glacial.

Foram estudadas 16 variedades, sendo empregado um delineamento experimental em látice quadrado $4 \times 4$, com cinco repetições. Das variedades estudadas, 12 pertenciam ao grupo "CB.", sendo comparadas com quatro variedades do grupo "Co.", já bem conhecidas. Constaram do ensaio as variedades seguintes: CB. 36/14, CB. 36/24, CB. $38 / 22$, CB. $38 / 30$, CB. $40 / 7$, CB. $40 / 13$, CB. $40 / 19$, CB. $40 / 69$, CB. $40 / 77$, CB. $41 / 35$, CB. $41 / 70$, CB. 41/76, Co. 290, Co. 413, Co. 421 e Co. 419. Nos ensaios localizados nas usinas Tamôio e Pôrto Feliz a CB. 40/77 foi substituida pela variedade N:Co. 352. Posteriormente verificou-se que a CB. $36 / 14$ e a $C B .36 / 24$ eram uma mesma variedade, ou seja, a CB. $36 / 14$.

Os canteiros eram constituídos por cinco linhas de $8 \mathrm{~m}$ de comprimento, espaçadas de $1,50 \mathrm{~m}$. As duas linhas laterais de cada canteiro foram consideradas marginais, sendo cortadas por ocasião da coIheita apenas as três linhas centrais. A área útil de cada canteiro foi, portanto, de $36 \mathrm{~m}^{2}(4,50 \times 8,00)$. 
Todos os ensaios foram adubados com fórmulas usadas pelas respectivas usinas; essas adubações serão mencionadas na descrição de cada ensaio. Foram utilizadas mudas de três gemas, provenientes de cana com 12 mêses de idade.

Os ensaios foram plantados em princípios de 1953, sendo o primeiro corte feito com aproximadamente 18 meses e os seguintes com intervalos aproximados de um ano, como se procede normalmente na cultura da cana de açúcar. Analizaram-se as produções do primeiro corte e também a soma das produções dos três cortes. Estudaram-se ainda os dados obtidos no segundo e terceiro cortes, o que permite avalior a queda de produção das diversas variedades, de um corte para o outro. Para o cálculo teórico do açúcar produzido foi usada a fórmula de Winter-Carp, Geerligs, modificada por Arceneaux, usando-se os fatôres 0,985 e 0,970 para correção do brix e sacarose, respectivamente, $76 \%$ para extração e $88 \%$ como eficiência das caldeiras ( 1 ).

No ensaio da Usina Itaiquara efetuaram-se apenas dois cortes, não tendo sido possível fazer o terceiro, devido à má brotação da ressoca.

No ensaio da Usina Monte Alegre não se fêz a análise química do caldo no segundo corte; para o cálculo do açúcar provável, usaram-se as análises do terceiro corte.

Tomou-se como têrmo de comparação a variedade Co. 419 , uma vez que, na maiorio dos ensaios, o comportamento da Co. 290 não foi satisfatório.

\section{3 - RESULTADOS}

Os resultados obtidos serão apresentados à medida que forem sendo descritos os diversos ensaios.

As diferenças mínimas significativas apresentadas referem-se sempre às produções médias das cinco repetições.

\section{1 - ENSAIO NA USINA SANTA ELISA}

$O$ ensaio instalado nesta usina, localizada no município de Sertãozinho, foi plantado em terra-roxa-misturada de boa fertilidade, no dia 11 de fevereiro de 1953, tendo sido adubado na base de 800 quilos por hectare de uma mistura contendo $15 \mathrm{~kg}$ de azôto orgânico, $110 \mathrm{~kg}$ de $\mathrm{P}_{2} \mathrm{O}_{5}$ e $56 \mathrm{~kg}$ de $\mathrm{K}_{2} \mathrm{O}$. Alguns meses após o plantio, em julho, foi o ensaio atingido por geadas que queimaram completa- 
mente as touceiras já formadas. Isto, porém, não inutilizou o ensaio pois a cana brotou novamente e muito bem. O estado sanitário das variedades não era satisfatório, apresentando-se quase tôdas com apreciável ataque de mosaico. O primeiro corte foi feito em 25 de agôsto de 1954, o segundo em 25 e 26 de agôsto de 1955 e o terceiro em 23 e 24 de agôsto de 1956. A germinação do ensaio foi boa, com exceção de um dos tratamentos, constituido pela CB. 36/14 (justamente o que deveria ser a CB. 36/24). Em vista destes fatos, repetição de uma variedade, CB. 36/14, e baixa germinação de um tratamento da variedade repetida, foi ela eliminada neste ensaio, procedendo-se à análise estatística como blocos ao acaso, com 15 variedades e cinco repetições. Antes, porém, procurou-se fazer a análise como látice quadrado com 16 variedades obtendo-se uma eficiência mínima. Os resultados obtidos nesse ensaio figuram no quadro 1 .

A análise da variância dos dados do primeiro corte revelou efeito altamente significativo devido a variedades e não significativos devido a repetições, tanto em produção de cana como de açúcar provável, conforme se verifica o seguir.

a) Produção de cana:

\begin{tabular}{|c|c|c|c|c|}
\hline Fontes de varioção & G. L. & S. Q. & Q. M. & $F$ \\
\hline 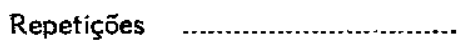 & 4 & 727,48 & 181,87 & 1,85 \\
\hline Variedades & 14 & 10120,64 & 722,90 & $7,34 * *$ \\
\hline Erro & 56 & 5513,01 & 98,45 & \\
\hline Total & 74 & 16361,13 & & \\
\hline
\end{tabular}

D. m. s. $=12,8$

Coef. de variação $=9,2 \%$

b) Produção de açúcar:

\begin{tabular}{|c|c|c|c|c|}
\hline Fontes de variação & G. L. & S. Q. & Q. M. & $\mathbf{F}$ \\
\hline (n) & 4 & 9,9245 & 2,481 & 1,76 \\
\hline (n) & 14 & $178,357 \mid$ & 12,740 & $9,05^{* *}$ \\
\hline Êrro & 56 & 78,8722 & 1,408 & \\
\hline Total & 74 & 267,1538 & & \\
\hline
\end{tabular}

D. m. s. $=1,53$

Coef. de variação $=9,1 \%$ 


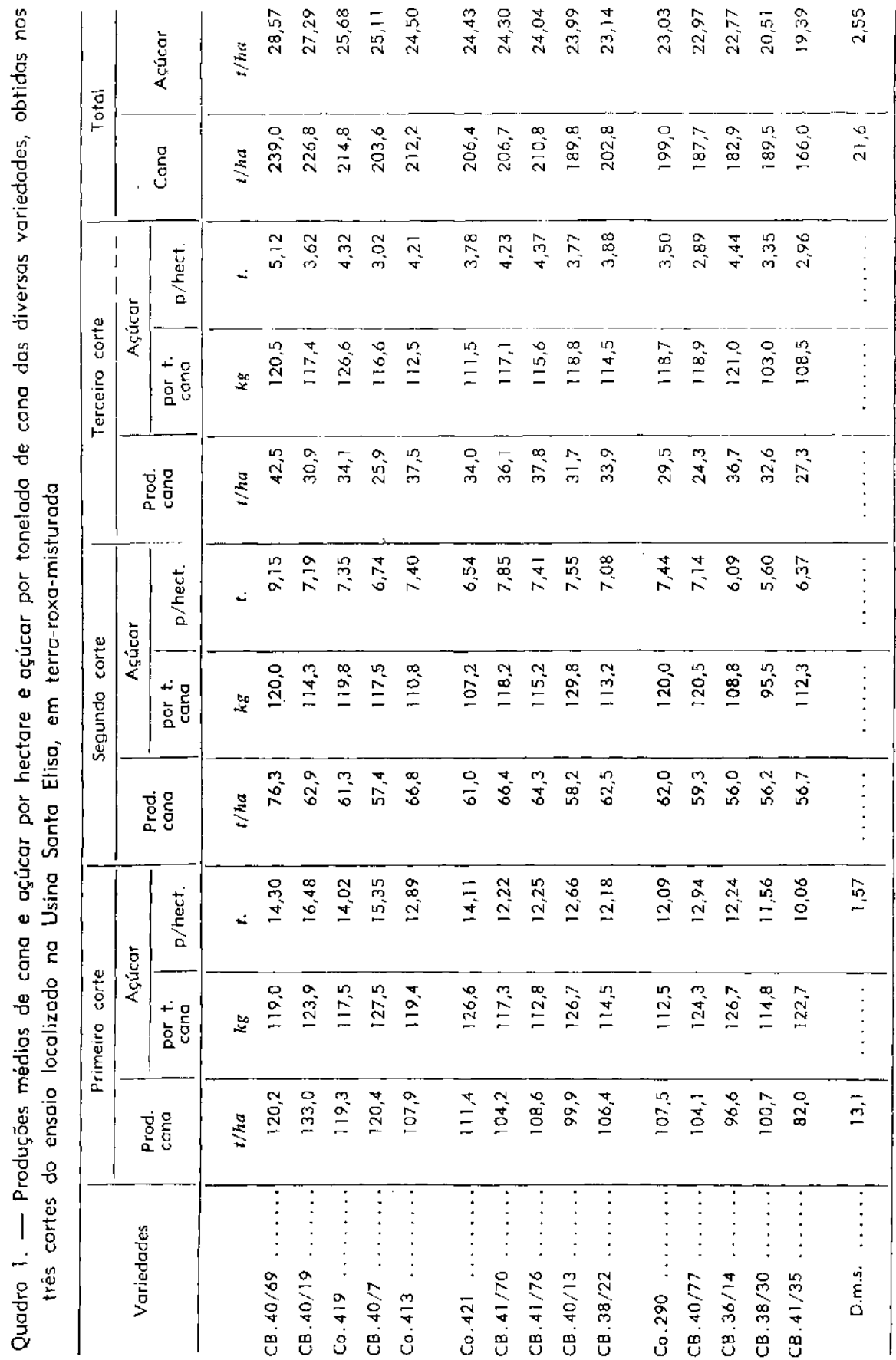


Os dados obtidos no primeiro corte revelaram que, em produção de cana, a CB. 40/19 foi superior à Co. 419. Igualaram-se a esta variedade as seguintes: CB. 40/7, CB. 40/69, Co. 421, CB. 41/76, Co. 413 e Co. 290. Inferiores à Co. 419 mostraram-se as variedades $C B$. $38 / 22$, CB. $41 / 70, C B .40 / 77, C B .38 / 30, C B .40 / 13, C B .36 / 14$ e CB. $41 / 35$.

Em produção de açúcar, devido ao seu diferente teor o comportamento das variedades não foi o mesmo. Assim é que CB. 40/77 e CB. 40/13, que apresentaram produções de cana inferiores à da Co. 419, igualaram-se a ela em produção de açúcar devido à sua maior riqueza. Enquanto isso as variedades CB. 41/76 e Co. 290, que tiveram produção de cana igual à da Co. 419, foram inferiores a ela em produção de açúcar. Dentre as variedades que se mostraram inferiores à Co. 419, a CB. 36/14 apresentou alta produção de açúcar por tonelada de cana, dando-se o inverso com as CB. $38 / 22$ e $38 / 30$.

Quando se consideraram os totais dos três cortes, a análise da variância revelou, como no primeiro corte, um efeito altamente significativo devido a variedades e não significativo devido a repetições, conforme se verifica a seguir.

a) Produção de cana:

\begin{tabular}{|c|c|c|c|c|}
\hline Fontes de variação & G. L. & S. Q. & Q.M. & $\mathrm{F}$ \\
\hline Repetições & 4 & 2139,85 & 534,96 & 1,89 \\
\hline Variedades & 14 & 21648,29 & 1546,29 & $5,46 * *$ \\
\hline Érro & 56 & 15849,63 & 283,03 & \\
\hline - & 74 & 39637,57 & & \\
\hline
\end{tabular}

D.m. s. $=21,7$

Coef. de variação $=8,3 \%$

b) Produção de açúcar:

\begin{tabular}{|c|c|c|c|c|}
\hline Fontes de variação & G. L. & S. Q. & Q. M. & $\mathrm{F}$ \\
\hline $\begin{array}{l}\text { Repetições } \\
\text { Voriedades } \\
\text { Érro } \\
\quad \text { Total }\end{array}$ & $\begin{array}{r}4 \\
14 \\
56 \\
74\end{array}$ & $\begin{array}{r}27,6336 \\
370,0510 \\
221,4289 \\
619,1135\end{array}$ & $\begin{array}{r}6,908 \\
26,432 \\
3,954\end{array}$ & $\begin{array}{l}1,75 \\
6,68^{* *}\end{array}$ \\
\hline
\end{tabular}

D. m. s. $=2,57$

Coef. de variação $=8,3 \%$ 
Vol. 17, N. 4

Analisando-se as produções totais do ensaio verificou-se que a CB. 40/69 foi superior à Co. 419 tanto em produção de cana como de açúcar. Revelaram-se iguais à Co. $419 \mathrm{em}$ produção de cana as variedades CB. 40/19, Co. 413, CB. 41/76, CB. 41/70, Co. 421, CB. $40 / 7$, CB. $38 / 22$ e Co. 290. Dentre estas a CB. $40 / 19$ foi superior às três últimas. Tiveram produções de cana inferiores à Co. 419 as seguintes variedades: CB. 40/13, CB. 38/30, CB. 40/77, CB. 36/14, e CB. 41/35. A CB. 40/13, que teve produção de cana inferior à da Co. 419, igualou-se a esta em produção de açúcar, enquanto que a Co. 290 , com produção de cona igual à da Co. 419 , revelou-se inferior a ela na produção de açúcar.

Por sua vez a CB. 40/19 foi superior em produção de açúcar a tôdas as variedades que haviam se revelado iguais à Co. 419 , ou sejam Co. 413, CB. $41 / 76$, CB. $41 / 70$, Co. 421 e CB. 38/22. A CB. $40 / 7$, que fôra inferior à $C B$. 40/19 em produção de cona, igualou-se a ela na produção de açúcar. A Co. 290 foi superior apenas à CB. $41 / 35$, tanto em produção de cana como de açúcar.

\section{2 - ENSAIO NA USINA TAMOIO}

O ensaio efetuado nesta usina, localizada no município de Aroraquara, foi plantado em 14 de fevereiro de 1953, em terra-roxa-misturada de fertilidade média. Recebeu, por ocasião do plantio, uma adubação na base de $35 \mathrm{~kg}$ de $\mathrm{N}, 90 \mathrm{~kg}$ de $\mathrm{P}_{2} \mathrm{O}_{5}$ e $50 \mathrm{~kg}$ de $\mathrm{K}_{2} \mathrm{O}$ por hectare. A brotação do ensaio foi muito boa, apresentando as diversas variedades boa sanidade, com pequena porcentagem de mosaico. Também êste ensaio foi atingido por geadas, porém levemente, não chegando a ser prejudicado. O primeiro corte do ensaio foi feito em 18 de agôsto de 1954, o segundo em 11 de agôsto de 1955 e o terceiro em 14 de agôsto de 1956. Em Tamôio a CB. 40/77 foi substituida pela $\mathrm{N}$ : Co. 352 . Os resultados obtidos figuram no quadro 2, devendo-se observar que as produções totais dos três cortes foram corrigidas de acôrdo com o delineamento experimental empregado.

A aplicação do látice quadrado aos dados do primeiro corte não apresentou eficiência alguma, razão pela qual a análise estatística foi feita como blocos ao acaso. A onálise da variância revelou efeitos altamente significativos para repetições e variedades, tanto na produção de cana como de açúcar provável, como se vê a seguir. 
Segalla \& Alvarez

Nov., 1958 Variedades de Cana-DE-AÇúCar. II.

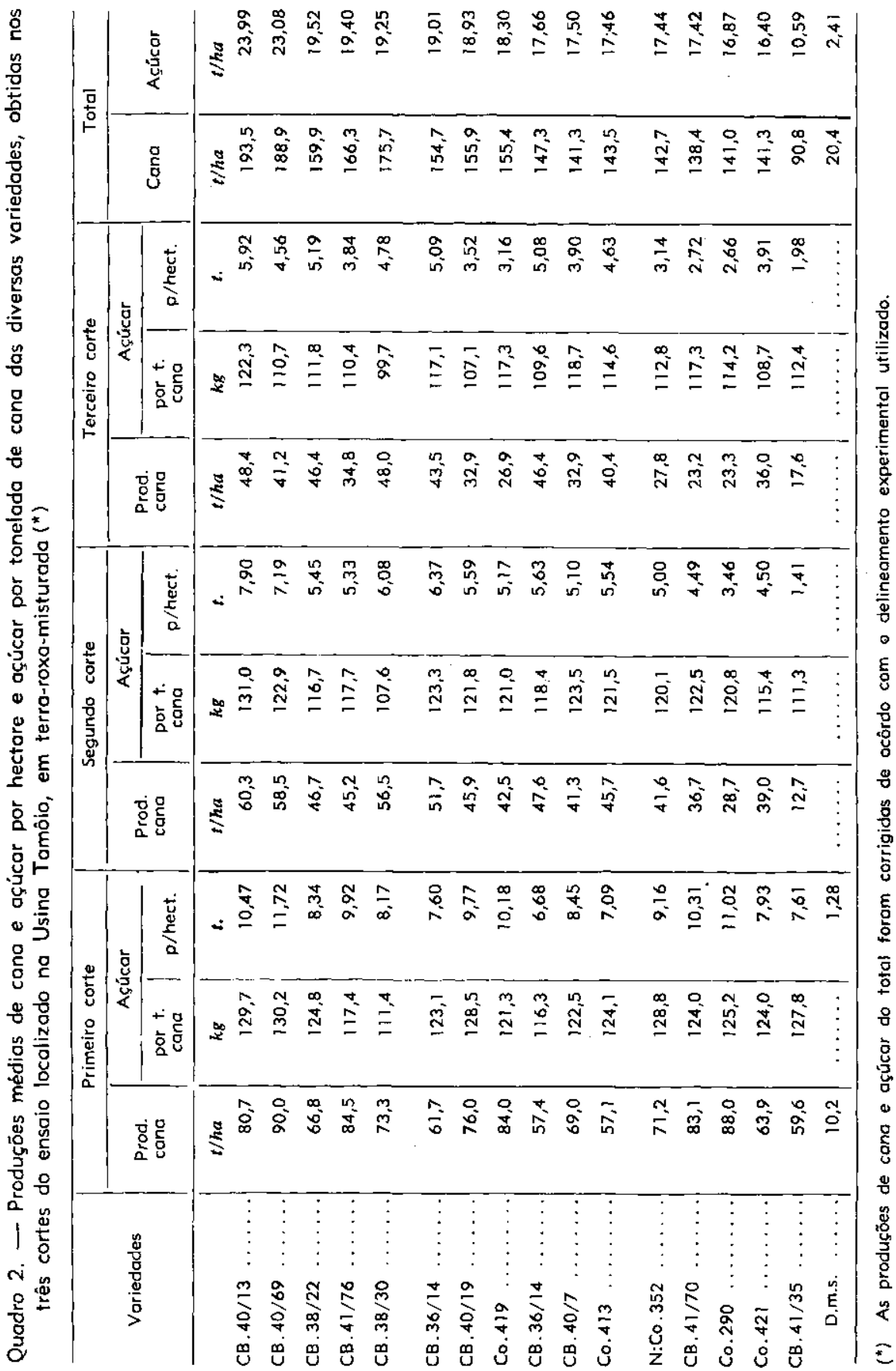


a) Produção de cana:

\begin{tabular}{l|r|r|r|r|r}
\hline \multicolumn{1}{c|}{ Fontes de variação } & G. L. & S. Q. & Q. M. & \multicolumn{1}{c}{ F } \\
\hline Repetiçöes & & 4 & 951,66 & $237,9 \mathrm{I}$ & $3,79^{* *}$ \\
Variedades & & 15 & 9389,83 & 625,99 & $9,96^{*}$ \\
Êrro & 60 & 3770,88 & 62,85 & \\
$\quad$ Total & & & & \\
\hline
\end{tabular}

D. m. s. $=10,2$

Coef. de variação $=10,9 \%$

b) Produção de açúcar:

\begin{tabular}{|c|c|c|c|c|}
\hline Fontes de variaçäo & G. L. & S. Q. & Q. M. & $\mathrm{F}$ \\
\hline Repetiçōes & 4 & 14,6950 & 3,673 & 3,75 * * \\
\hline Variedades & 15 & 168,3008 & 11,220 & $11,45^{* *}$ \\
\hline Êrro & 60 & 58,7960 & 0,980 & \\
\hline Total & 79 & & & \\
\hline
\end{tabular}

Observando-se as produções do primeiro corte verificou-se que nenhuma variedade foi superior à Co. 419. Igualaram-se a esta, em produção de cana, as variedades CB. 40/69, Co. 290, CB. 41/76, CB. $41 / 70, C B .40 / 13$ e CB. $40 / 19$, sendo que as duas primeiras foram superiores à $C B$. 40/19. Além destas variedades também a $\mathrm{N}$ : Co. 352, que foi inferior à Co. 419 em produção de cana, igualou-se a ela em produção de açúcar, devido à riqueza em açúcar que apresentou. As demais variedades foram inferiores à Co. 419 , tonto em produção de cana como de açúcar.

Dentro de cada grupo houve diferenças na produção de açúcar em relação à produção de cana; assim é que no primeiro grupo a CB. 40/19, que se mostrou inferior à CB. 40/69 e à Co. 290 em produção de cana, igualou-se à Co. 290 em produção de açúcar, continuando ainda inferior à CB. 40/69, enquanto que a CB. 41/76, que se tinha igualado à última em produção de cana, mostrou-se inferior a ela na produção de açúcar. Também a CB. 40/13, devido d̀ maior riqueza em açúcar apresentada, melhorou sua posição, neste particular, em relação às outras variedades. 
Entre as variedades que se mostraram inferiores d̀ Co. 419, a CB. $38 / 30$, que havio superado as voriedades CB. 36/14, CB. 41/35 e Co. 413 em produção de cana, devido à sua menor riqueza igualou-se a elas na produção de açúcar.

Quando se considerou o total dos três cortes a análise da variância revelou efeitos altamente significativos para repetições e variedades, tanto em produção de cana como de açúcar provável. A aplicação do látice quadrado aos dados de produção de cana proporcionou uma eficiência de $12,3 \%$ a mois do que a análise em blocos ao acaso, ficando o coeficiente de variação reduzido de 11 para $10,4 \%$. Na produção de açúcar a eficiência obtida com a aplicação do látice quadrado foi de $17,3 \%$, sendo o coeficiente de variação reduzido para $10,2 \%$. A análise da variância do total dos três cortes figura a seguir.

a) Produção de cana:

\begin{tabular}{|c|c|c|c|}
\hline Fontes de variação & G. L. & S. Q. & Q. M. \\
\hline 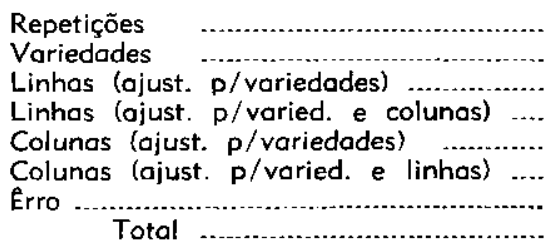 & $\begin{array}{l}4 \\
15 \\
15 \\
15 \\
15 \\
15 \\
30 \\
79\end{array}$ & $\begin{array}{rr}7396,36 \\
41435,33 \\
6173,80 \\
6380,93 \\
2490,55 \\
2697,68 \\
8005,36\end{array}$ & $\begin{array}{l}1849,09 \\
2762,36 \\
411,59 \\
425,39(\mathrm{Er}) \\
166,04 \\
179,85(\mathrm{Ec}) \\
266,85(\mathrm{Ee})\end{array}$ \\
\hline
\end{tabular}

b) Produção de açúcar:

\begin{tabular}{|c|c|c|c|}
\hline Fontes de voriação & G. L. & S. Q. & Q. M. \\
\hline $\begin{array}{l}\text { Repetiçöes } \\
\text { Variedodes } \\
\text { Linhas (ajust. p/variedades) } \\
\text { Linhas (ajust. p/varied. e colunas) } \\
\text { Colunas (ajust. p/variedades) } \\
\text { Colunas (ajust. p/varied. e linhas) } \\
\text { Êrro }\end{array}$ & $\begin{array}{l}4 \\
15 \\
15 \\
15 \\
15 \\
15 \\
30 \\
79\end{array}$ & $\begin{array}{r}107,7486 \\
639,3677 \\
91,0062 \\
94,1762 \\
33,0577 \\
36,2277 \\
116,1685\end{array}$ & $\begin{array}{l}26,437 \\
42,625 \\
6,067 \\
6,278(\mathrm{Er}) \\
2,204 \\
2,415 \text { (Ec) } \\
3,872 \text { (Ee) }\end{array}$ \\
\hline
\end{tabular}


Observando-se os dados totais dos três cortes, verifica-se que foram superiores à Co. 419 , tanto em produção de cana como de açúcar, as variedades CB. 40/13 e CB. 40/69. A CB. 38/300, conquanto tenha superado a Co. 419 em produção de cana, igualou-se a ela na produção de açúcar. As outras variedades mostraram-se iguais à Co. 419 tanto em produção de cana como de açúcar, com exceção da CB. $41 / 35$, inferior a tôdas as outras.

Embora as outras variedades tenham se. igualado à Co. 419, houve diferenças entre elas. Assim, a CB. 41/76 superou em produção de cana as variedades Co. $413, \mathrm{~N}$ :Co. $352, \mathrm{CB} .40 / 7$, Co. 421, Co. 290 e CB. 41/70, sendo que as três primeiras igualoram-se à $C B$. 41/76 em produção de açúcar.

Também as variedades CB. $38 / 22$ e $38 / 30$ foram superiores às Co. 290 e 421 em produção de cana e de açúcar. Ainda neste ensaio a Co. 290 só superou a CB. 41/35. Verifica-se pelos dados de açúcar por tonelada de cana, apresentados no quadro 2, que a CB. 40/13 apresentou alto teor em açúcar. Já as CB. 41/76 e 38/30 apresentaram baixa riqueza em açúcar, principalmente a última. As demais variedades, com exceção de um tratamento da CB. 36/14, apresentaram bons teores em açúcar no primeiro corte, caindo algumas no segundo corte e outras, no terceiro.

\section{3 - ENSAIO NA USINA PORTO FELIZ}

Êste ensaio, plantado no dia 14 de março de 1953 em terra-roxamisturada do glacial, foi localizado na Fazenda Capuava, na Usina Pôrto Feliz, no município do mesmo nome. O ensaio foi adubado na base de 30 toneladas de estêrco, $630 \mathrm{~kg}$ de torta de amendoim, $250 \mathrm{~kg}$ de farinha de chifres e $50 \mathrm{~kg}$ de cloreto de potássio por hectare. As geadas de julho de 1953 atingiram também êste ensaio, porém sem causar-lhe danos. As variedades estavam pouco atacadas de mosaico, apresentando tôdas elas bom aspecto sanitário. $O$ primeiro corte foi feito nos dias 12 e 13 de agôsto de 1956. Pouco antes do segundo corte, em julho de 1955, o ensaio foi atingido novamente por geadas, pouco alterando, porém, o teor em açúcar das variedades; por ocasião do terceiro corte a maturação das variedades foi um pouco alterada, desta vez pelas chuvas constantes do inverno de 1956. Também neste ensaio a CB. $40 / 77$ foi substituida pela N:Co. 352 . Os resultados obtidos no ensaio figuram no quadro 3 , devendo-se observar que as pro- 
Segalla \& Alvarez

Nov., 1958 Variedades DE CANA-DE-AçúCar. II.

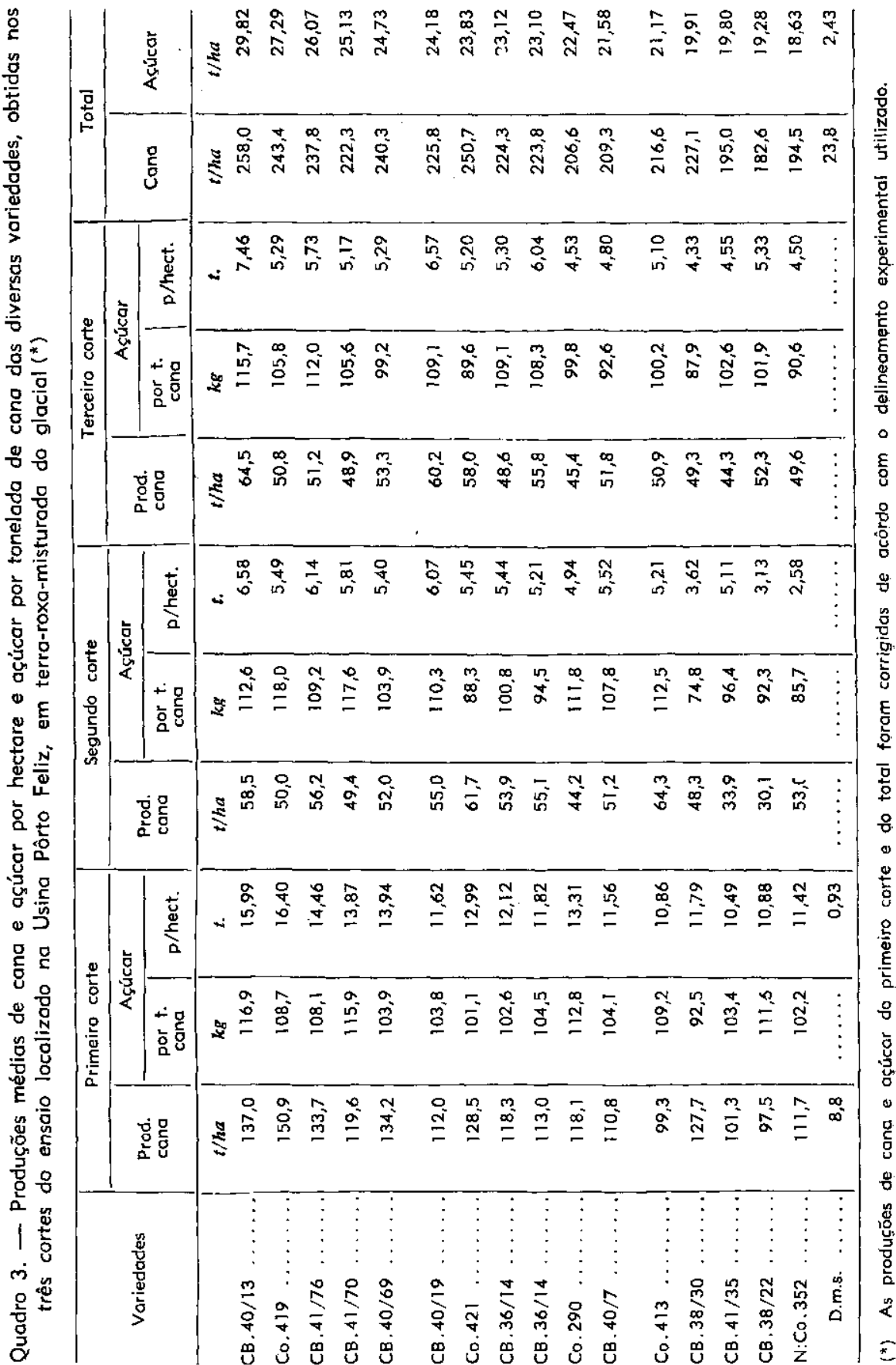


VoL. 17, N.o 4

duções de cana e açúcar do primeiro corte e do total dos três cortes foram corrigidas de acôrdo com o delineamento experimental empregado.

Considerando-se os dados do primeiro corte, tanto em produção de cana como de açúcar, verificou-se que a análise da variância revelou efeitos altamente significativos para repetições e para variedades. A aplicação do látice quadrado aos dados de produção de cana proporcionou uma eficiência de $25,7 \%$ e de $25,4 \%$ na produção de açúcar, em relação à análise feita como blocos ao acaso, o coeficiente de variação sendo reduzido de 6,4 para $5,7 \%$ em ambos os casos.

Figuram a seguir os quadros da análise estatística como látice quadrado.

a) Produçäo de cona:

\begin{tabular}{|c|c|c|c|}
\hline Fontes de variação & G. L. & S. Q. & Q. M. \\
\hline 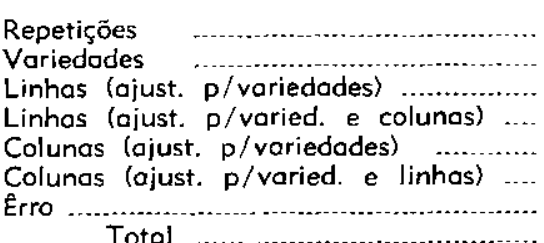 & $\begin{array}{l}4 \\
15 \\
15 \\
15 \\
15 \\
15 \\
30 \\
79\end{array}$ & 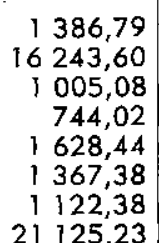 & $\begin{array}{c}346,70 \\
1082,91 \\
67,01 \\
49,60(\mathrm{Er}) \\
108,56 \\
91,16(\mathrm{Ec}) \\
37,41(\mathrm{Ee})\end{array}$ \\
\hline
\end{tabular}

D. m. s. $=8,8$

Coef. de variação $=5,7 \%$

b) Produção de açúcar:

\begin{tabular}{|c|c|c|c|}
\hline Fontes de variação & G. L. & S. Q. & Q. M. \\
\hline $\begin{array}{l}\text { Repetições } \\
\text { Variedades } \\
\text { Linhas (ajust. p/variedades) } \\
\text { Linhas (ajust. p/voried. e colunas) } \\
\text { Colunas (ajust. p/variedades) } \\
\text { Colunas (ajust. p/varied. e linhos) } \\
\text { Êrro }\end{array}$ & $\begin{array}{l}4 \\
15 \\
15 \\
15 \\
15 \\
15 \\
30 \\
79\end{array}$ & $\begin{array}{r}15,7001 \\
236,5749 \\
11,0938 \\
8,1648 \\
18,4083 \\
15,4793 \\
12,7884 \\
291,6365\end{array}$ & $\begin{array}{l}3,925 \\
15,772 \\
0,740 \\
0,544(\mathrm{Er}) \\
1,227 \\
1,032(\mathrm{Ec}) \\
0,426(\mathrm{Ee})\end{array}$ \\
\hline
\end{tabular}


Observando-se as produções do primeiro corte verifica-se que a Co. 419 foi superior a tôdas as variedades em produção de cana, sendo que na produção de açúcar apenas a CB. 40/13 igualou-se a ela.

Considerando-se a produção de açúcar, pode-se destacar, a seguir, um segundo grupo constituido pelas variedades $\mathrm{CB}$. 41/76, CB. 40/69, CB. 41/70; quando se considera apenas a produção de cana, o segundo grupo é constituido pelas variedades CB. 40/13, CB. 40/69, CB. $41 / 76$, Co. 421 e CB. $38 / 30$. Nota-se que a menor riqueza em açúcar excluiu do segundo grupo a Co. 421 e a CB. 38/30, enquanto que a maior riqueza apresentada pela $C B$. 41/70 fêz com que fôsse ela colocada nesse grupo, quando se considerou a produção de açúcar.

Também na produção total dos três cortes a análise da variância revelou efeitos altamente significativos devido a variedades e a repetições, tanto em produção de cana como de açúcar. A eficiência da aplicação do látice quadrado, em relação à análise como blocos ao acaso, foi bem menor que no primeiro corte, 9,2\% para os dados de produção de cana e $11,4 \%$ para os de açúcar; quanto ao coeficiente da variação a redução foi muito pequena em ambos os casos. Os quadros relativos à análise da variância como látice quadrado figuram a seguir:

a) Produção de cana:

\begin{tabular}{|c|c|c|c|}
\hline Fontes de variaçăo & G. L. & S. Q. & Q.M. \\
\hline Repetições $\quad$ - & 4 & 9534,31 & 2. 383,58 \\
\hline Variedodes & 15 & 34761,05 & 2317,40 \\
\hline Linhas (ajust. p/variedades) & 15 & 8743,90 & 582,93 \\
\hline Linhas (ajust. p/varied. e colunas) .... & 15 & 9185,28 & $612,35(\mathrm{Er})$ \\
\hline Colunas (ajust. p/variedades) & 15 & 4421,60 & 294,77 \\
\hline Colunas (ajust. $p /$ varied. e linhas) $\ldots .$. & 15 & 4862,98 & $324,20(\mathrm{Ec})$ \\
\hline Êrro & 30 & 8768,11 & $292,27(\mathrm{Ee})$ \\
\hline Total & 79 & 66670,35 & \\
\hline
\end{tabular}

D. m. s. $=23,8$

Coef. de variação $=8,3 \%$ 
b) Produção de açúcar:

\begin{tabular}{|c|c|c|c|}
\hline Fontes de variação & G. L. & S. Q. & Q. M. \\
\hline $\begin{array}{l}\text { Repetições } \\
\text { Variedades } \\
\text { Linhas (ajust. p/variedades) } \\
\text { Linhas (ajust. p/varied. e colunas) } \\
\text { Colunas (ajust. p/variedades) } \\
\text { Colunas (ajust. p/varied. e linhas) } \\
\text { Êrro }\end{array}$ & $\begin{array}{l}4 \\
15 \\
15 \\
15 \\
15 \\
15 \\
30 \\
79\end{array}$ & $\begin{array}{r}99,5173 \\
708,6351 \\
87,7213 \\
89,8721 \\
53,5116 \\
55,6624 \\
93,2244 \\
1044,7605\end{array}$ & $\begin{array}{l}24,879 \\
47,249 \\
5,848 \\
5,991(\mathrm{Er}) \\
3,567 \\
3,711(\mathrm{Ec}) \\
3,107(\mathrm{Ee})\end{array}$ \\
\hline
\end{tabular}

Analisando-se as produções totais dos três cortes, verifica-se que nenhuma variedade foi superior à Co. $419 \mathrm{em}$ produção de cana. Igualaram-se a ela as variedades CB. 40/13, CB. 40/69, Co. 421 e CB. 41/76. Em produção de açúcar a CB. 40/13 foi superior à Co. 419, colocando-se em posição inferior a esta a CB. 40/69. As demais variedades do ensaio tiveram produções inferiores, estatisticamente, à $\mathrm{Co}$. 419 , sendo que em açúcar as variedades CB. 40/69 e CB. 40/19, conquanto inferiores à Co. 419, foram superiores às variedades $C B$. 40/7, Co. 413, CB. $38 / 30$, CB. $41 / 35$, CB. $38 / 22$ e N:Co. 352. A Co. 290 em produção de cana só foi superior à $C B$. 38/22 porém em açúcar superou também as variedades CB. 38/30, CB. 41/35 e N:Co. 352. Também neste ensaio a $\mathrm{CB}$. $38 / 30$ produziu menos açúcar por tonelada de cana que as outras variedades, enquanto a $C B .40 / 13$ produziu mais.

\section{4 - ENSAIO NA USINA ITAIQUARA}

O ensaio instalado na Usina Itaiquara, situado no município de Tapiratiba, foi localizado em terra-massapê-salmourão, de média fertilidade. Seu plantio foi feito em 24 de março de 1953. Em julho dêsse mesmo ano foi o ensaio atingido pelas geadas, sendo bastante queimado; tôdas as variedades, porém, reagiram muito bem apresentando nova e ótima brotação, inclusive a $C B$. 38/30, que não tinha apresentado boa brotação inicial. Depois de alguns meses foi feita uma verificação do aspecto sanitário das variedades, em relação ao mosaico. Verificou-se que estavam intensamente atacadas as CB. 41/70, CB. 
$41 / 35$ e Co. 419; muito atacadas estavam as CB. 36/14, 41/76, $40 / 77,40 / 69$ e Co. 290; a CB. 40/13 pouco atacada e com pouquíssimos casos, as Co. 413 e 421 e as CB. 38/22, 40/19, 38/30 e 40/7. Neste ensoio foram feitos apenas dois cortes, o primeiro em 9 de setembro de 1954 e o segundo em 31 de agôsto de 1955. Não foi feito o terceiro corte pelo motivo já exposto, devendo-se acrescentar que pouco antes do segundo corte, em julho de 1955, foi o ensaio novamente atingido por geadas. A análise química do caldo revelou baixo teor em açúcar em tôdas as variedades, consequiência das geadas mencionadas.

Neste ensaio, por engano havido ao nos serem fornecidas as mudas, a Co. 421 ficou substituida pela CP. 27/139. Os resultados obtidos nos dois cortes do ensaio figuram no quadro 4 .

Considerando-se as produções do primeiro corte, a análise da variância revelou efeitos altamente significativos para repetições e variedades, tonto em produção de cana como de açúcar, conforme se verifica a seguir.

a) Produção de cana:

\begin{tabular}{|c|c|c|c|c|}
\hline Fontes de variaçõo & G. L. & S. Q. & Q. M. & $\mathbf{F}$ \\
\hline (1) & 4 & 3494,01 & 873,50 & $6,55^{* *}$ \\
\hline Variedades & 15 & 23118,07 & 1541,20 & $11,55^{* *}$ \\
\hline Êrro & 60 & 8004,23 & 133,40 & \\
\hline Total & 79 & 34616,31 & & \\
\hline
\end{tabular}

b) Produção de açúcar:

\begin{tabular}{l|r|r|r|r}
\hline \multicolumn{1}{c|}{ Fontes de variação } & G. L. & S. Q. & S. Q. & \multicolumn{1}{c}{ F } \\
\hline Repetiçōes & 4 & 56,2303 & 14,058 & $6,56^{* *}$ \\
Voriedades & 15 & 380,0904 & 25,339 & $11,82^{* *}$ \\
Erro & 60 & 128,6285 & 2,144 & \\
Total & 79 & 564,9492 & \\
\hline \\
D. m. s. $=1,89$
\end{tabular}




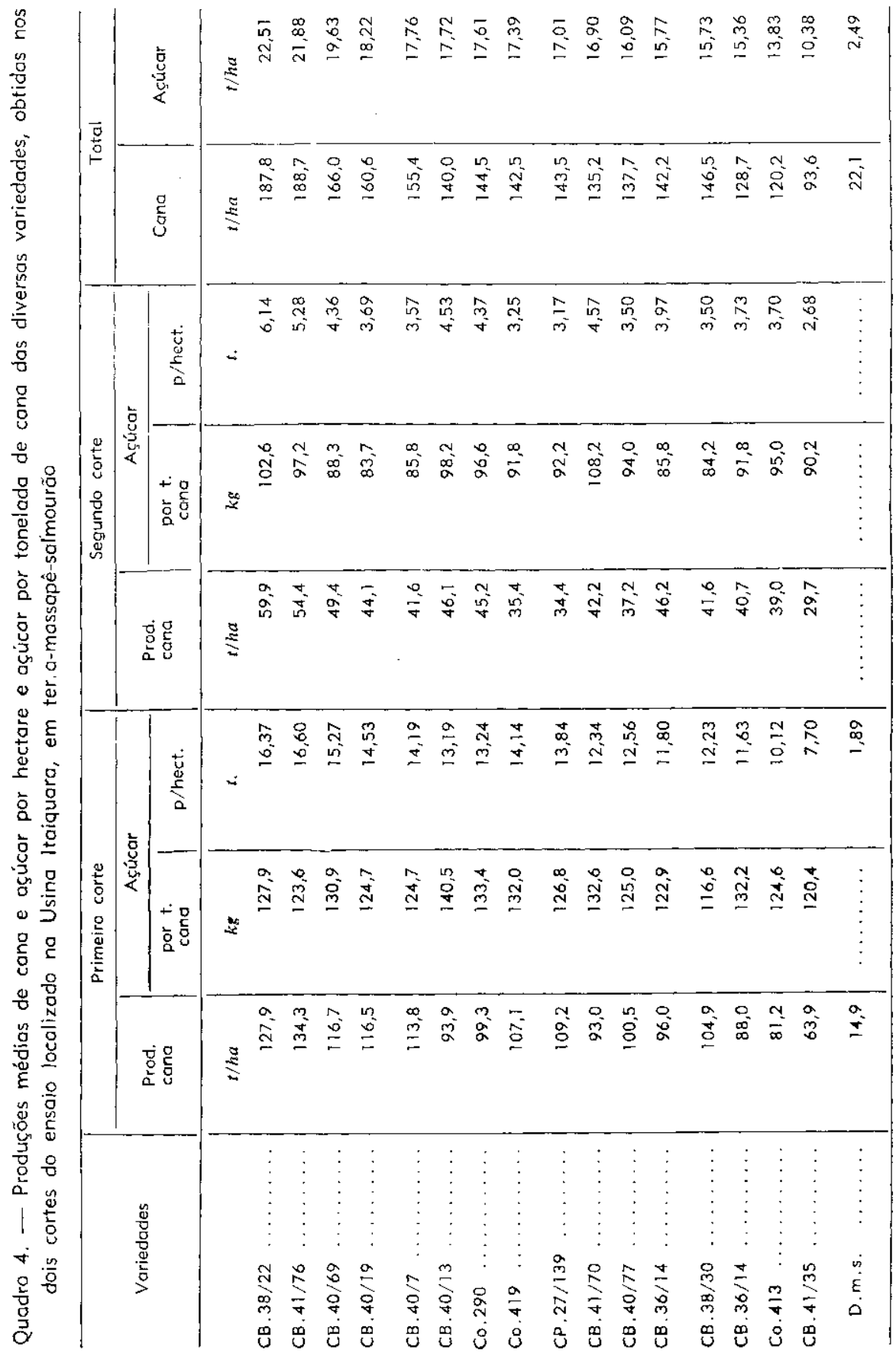


Observando-se as produções dêsse primeiro corte verifica-se que as variedades CB. $41 / 76$ e CB. $38 / 22$ foram superiores à Co. 419 , tanto em produção de cana como de açúcar. Igualaram-se à Co. 419 as variedades CB. 40/69, CB. 40/19, CB. 40/7, CP. 27/139, CB. $38 / 30$, CB. $40 / 77$, Co. 290 , um tratamento da CB. 36/14, CB. 40/13 e CB. 4I/70. Em produção de açúcar a $C B .38 / 30$, devido à menor riqueza, foi inferior à $\mathrm{Co} .419$, o mesmo acontecendo com a $C B .36 / 14$ que havia se igualado à Co. 419 em produção de cana. A CB. 40/13, variedade rica em açúcar, melhorou sua posição em relação à produção de cana, enquanto a CB. 38/30 também neste ensaio revelou ser menos rica em açúcar. Foram inferiores à Co. 419, tanto em cana como em açúcar, as variedades CB. 36/14, Co. 413 e CB. 41/35.

Quando se observou a produção total dos dois cortes a análise da variância também revelou um efeito altamente significativo devido a repetições e a variedades, como se verifica em seguida.

a) Produção de cana:

\begin{tabular}{|c|c|c|c|c|}
\hline Fontes de variação & G. L. & S. Q. & Q. M. & $\mathbf{F}$ \\
\hline Repetiçōes & 4 & 5141,56 & 1285,39 & $4,40^{* *}$ \\
\hline Voriedades & 15 & 41172,04 & 2744,80 & $9,33^{* *}$ \\
\hline Êrro & 60 & 17648,68 & 294,14 & \\
\hline 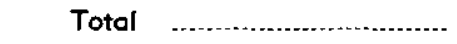 & 79 & 63962,28 & & \\
\hline
\end{tabular}

D. m. s. $=22,1$

Coef. de variação $=11,8 \%$

b) Produção de açúcar:

\begin{tabular}{|c|c|c|c|c|}
\hline Fontes de varioçäo & G. L: & S. Q. & Q. M. & $F$ \\
\hline (.)........................... & 4 & 76,6444 & 19,161 & $5,16^{* *}$ \\
\hline 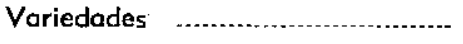 & 15 & 623,2413 & 41,549 & $11,19 * *$ \\
\hline Êrro & 60 & 222,8671 & 3,714 & \\
\hline Total & 79 & 922,7528 & & \\
\hline
\end{tabular}


VoL. 17 , N. 4

Observando-se os dados de produção dos dois cortes verifica-se que foram superiores à Co. 419 em produção de cana e açúcar as variedades $C B$. $38 / 22$ e CB. $41 / 76$, enquanto a CB. 40/69 foi superior à Co. 419 apenas em produção de cana. Revelaram-se iguais à Co. 419, tanto em produção de cana como em açúcar, as variedades CB. $40 / 19$, CB. $40 / 7$, CB. 40/13, Co. 290 , CP. 27/139, CB. 41/70, CB. $40 / 77, C B .36 / 14$ e CB. $38 / 30$, sendo que neste grupo, em produção de cana, a $C B$. 40/19 foi superior às variedades $C B$. 40/77, CB. 41/70 e CB. 36/14. Em produção de açúcar a $C B .40 / 69$ superou as variedades CP. 27/139, CB. 41/70, CB. 36/14 e CB. 40/77 enquanto a $C B .40 / 19$ só foi superior à $C B$. $38 / 30$. Inferiores à $C o$. 419 mostraram-se as variedades Co. 413 e CB. 4I/35.

Como nos ensaios anteriores, destacou-se pela alta produção de açúcar por tonelada de cana a CB. 40/13, dando-se o inverso com a CB. 38/30. Neste ensaio a Co. 290 superou as variedades Co. 413 e CB. $41 / 35$.

\section{$3.5-$ ENSAIO NA USINA SANTA BÄRBARA}

Êste ensaio, localizado na Usina Santa Bárbara, no município de Santa Bárbara do Oeste, foi plantado em terra arenosa do glacial, já bastante esgotada pelo cultivo sucessivo da cana-de-açúcar. Seu plantio foi feito em 10 de março de 1953 tendo sido o ensaio adubado com uma fórmula da usina. A brotação do ensaio foi boa, apresentando satisfatório estado sanitário. Devido a fogo no talhão em que estava localizado, o primeiro corte do ensaio foi feito relativamente cedo, em 20 de julho de 1954. O segundo corte foi feito em 24 de agôsto de 1955 e o terceiro em 21 de agôsto de 1956. Em vista das baixas produçōes obtidas no segundo corte, a administração da usina fêz uma adubação com torta de filtro após o segundo corte. Pouco antes dêsse corte foi o ensaio atingido por geadas, prejudicando a análise química do caldo das amostras. Também as análises do primeiro corte foram prejudicadas devido ao fogo. Os resultados obtidos nos três cortes do ensaio figuram no quadro 5 .

A análise da variância das produções de cana e açúcar do primeiro corte revelou efeitos altamente significativos para variedades e não significativos para repetições. A aplicação do látice quadrado a êsses dados não proporcionou eficiência, razão pela qual a análise 
Segalla \& Alvarez

Nov., 1958 Variedades DE CANA-DE-AÇÚCAR. II.

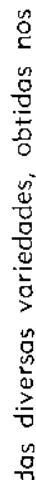

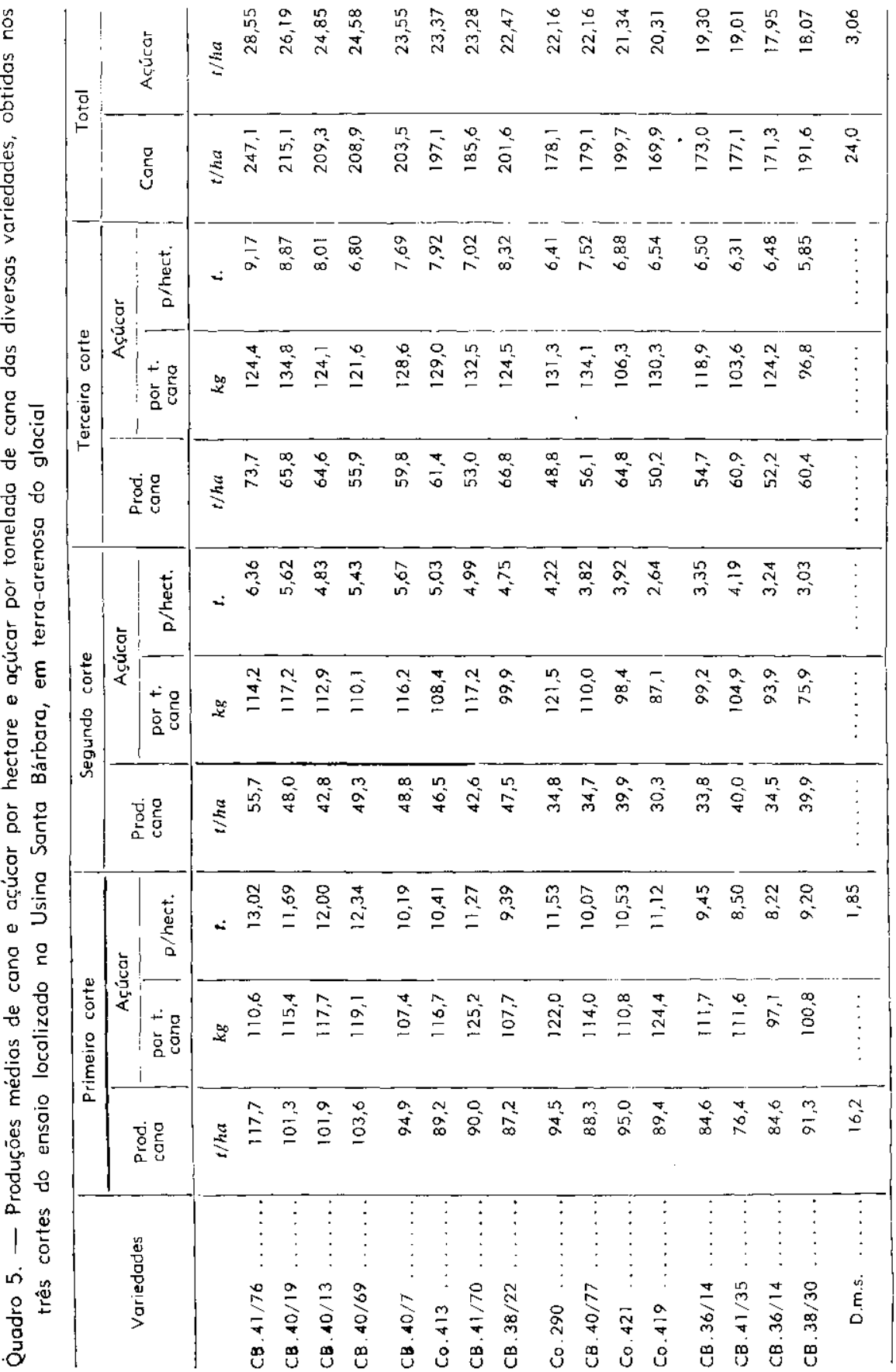


estatística foi feita como blocos ao acaso. A seguir figuram os quadros da análise da variâncio.

a) Produção de cona:

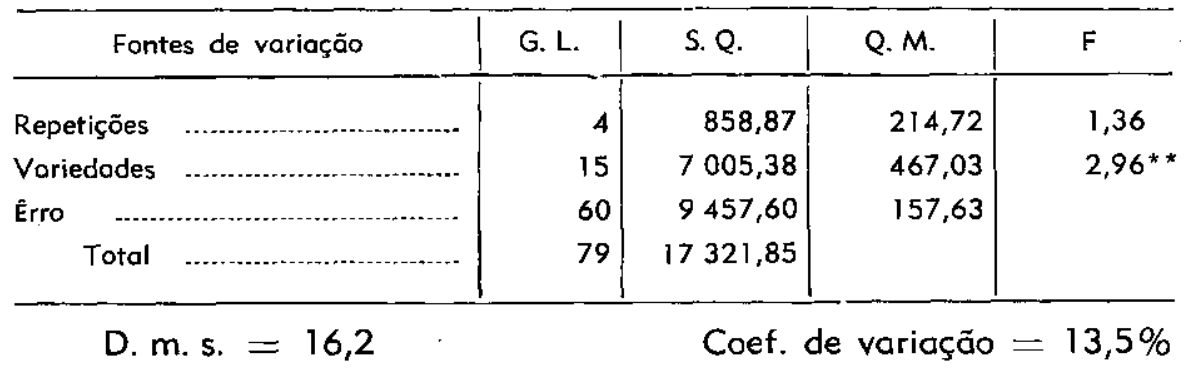

b) Produção de açúcar:

\begin{tabular}{|c|c|c|c|c|}
\hline Fontes de voriaçäo & G. L. & S. Q. & Q. M. & $\mathbf{F}$ \\
\hline 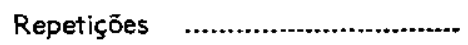 & 4 & 11,9218 & 2,980 & 1,46 \\
\hline Variedades & 15 & 144,4734 & 9,632 & $4,71^{* *}$ \\
\hline Érro & 60 & 122,8389 & 2,047 & \\
\hline Total & 79 & 279,2341 & & \\
\hline
\end{tabular}

Pelas produções obtidas nesse primeiro corte verificou-se que a CB. 41/76 foi superior à Co. 419 tanto em produção de cana como em açúcar. As demais variedades igualaram-se ò Co. 419 , com exceção das $C B$. $38 / 30$ e $41 / 35$, que foram inferiores a ela em produção de açúcar. Devem-se notar que as variedades CB. 40/69, CB. 40/13 e CB. 40/19, embora não tenham superado a Co. 419, igualaram-se à CB. 41/76 em produção de cana; em açúcor, além destas três mencionadas, também a Co. 290 e a CB. 41/70 se igualaram à CB. 41/76. Devido ao corte ter sido feito em meodos de julho, apenas as variedades CB. 41/70, Co. 419 e Co. 290 apresentavam bom teor de açúcar, seguidas por CB. 40/69, CB. 40/13, CB. 40/19 e CB. 40/77, com teor regular, sendo que as demais variedades apresentavam-no baixo, por ainda não terem completado sua maturação. 


\section{Segalla \& Alvarez}

Nov., 1958 VARIEdades dE CANA-DE-AÇúCAR. II.

67

A CB. 40/13, que em todos os outros ensaios foi das mais ricas em açúcar, no presente ensaio foi superada neste particular, pelas variedades CB. 41/70, Co. 419 e Co. 290. A CB. 38/30 também aqui revelou baixa produção de açúcar por tonelada de cana.

A aplicação do látice quadrado aos dados de produção total dos três cortes não revelou qualquer eficiência, razão pela qual a análise estatística foi feita como blocos ao acaso. A análise da variôncia mostrou, como no primeiro corte, efeitos altomente significativos para variedades e não significativos para repetições, como se verifica a seguir.

a) Produção de cana:

\begin{tabular}{|c|c|c|c|c|}
\hline Fontes de variaçäo & G. L. & S. Q. & Q. M. & $\mathrm{F}$ \\
\hline Repetições & 4 & 2123,97 & 530,99 & 1,23 \\
\hline Variedades & 15 & 31412,79 & 2094,18 & $4,86^{* *}$ \\
\hline Êrro & 60 & 25861,54 & 431,03 & \\
\hline Total & 79 & & & \\
\hline
\end{tabular}

D. m. s. $=24,0$

Coef. de variação $=10,7 \%$

b) Produção de açúcar:

\begin{tabular}{|c|c|c|c|c|}
\hline Fontes de variação & G. L. & S. Q. & Q.M. & $\mathbf{F}$ \\
\hline Repetiçōes & 4 & 28,3696 & 7,092 & 1,26 \\
\hline Variedades & 15 & 659,6188 & 43,974 & $7,82 *$ * \\
\hline Éro & 60 & 337,4932 & 5,623 & \\
\hline Total & 79 & 1025,4816 & & \\
\hline
\end{tabular}

D. m. s. $=3,06$

Coef. de variação $\doteq 10,6 \%$

Observando-se os dados de produção total dos três cortes verificouse que foram superiores à $\mathrm{Co}$. 419 , em produção de cana, as variedades CB. $41 / 76, C B .40 / 19$, CB. $40 / 13$, CB. $40 / 69$, CB. $40 / 7$, CB. $38 / 22$, Co. 421 e Co. 413. As demais igualaram-se à Co. 419, sendo que esta variedade foi a de menor produção. A CB. 41/76 foi superior a tôdas 
as outras variedades, tanto em produção de cana como de açúcar, com exceção da CB. 40/19 que se igualou a ela em produção de açúcar.

Em açúcar foram superiores à Co. 419, além da CB. $41 / 76$, as variedades CB. 40/19, CB. 40/13, CB. 40/69, CB. 40/7 e Co. 413. As demais igualaram-se d̀ Co. 419. Verifica-se que a $C B .38 / 22$ e a Co. 421 , que hoviam superado a Co. $419 \mathrm{em}$ produção de cana, igualaram-se a ela em açúcar. A Co. 419 , embora no primeiro corte tenha apresentado produção satisfatória, teve produções muito baixas em consequiência de diversos fatôres, contando-se entre êles: corte cedo em época sem chuva, e mau estado sanitário, possivelmente airida agravados pelo fogo. Êstes fotôres têm sido, comumente, a causa de má brotação das socas da Co. 419.

A Co. 290 só foi superior às variedades CB. 41/35, CB. 38/30 e CB. $36 / 14$, em produção de açúcar.

\section{6 - ENSAIO NA USINA MONTE ALEGRE}

O ensaio da usino Monte Alegre, situada no municipio de Piracicaba, foi instalado em terra-roxa-misturada de baixa fertilidade, esgotada por sucessivos plantios de cana-de-açúcar. Foi plantado em 2 de março de 1953 tendo sido adubado na base de $35 \mathrm{~kg}$ de azôto, $100 \mathrm{~kg}$ de $\mathrm{P}_{2} \mathrm{O}_{i 1}$ e $60 \mathrm{~kg}$ de $\mathrm{K}_{2} \mathrm{O}$, por hectare.

O primeiro corte foi feito em 5 de novembro de 1954, já bem tarde; o segundo, em 19 de novembro de 1955 e o terceiro em 26 de setembro de 1956. Não foi feita a análise química do caldo das variedades por ocasião do segundo corte. Para se poder apreciar a produção total de açúcar dos três cortes, calculou-se o açúcar provável do segundo corte, utilizando-se as análises do terceiro corte. Os resultodos obtidos figuram no quadro 6.

Feito o estudo estatístico das produções de cana e açúcar do primeiro corte, a análise da variâncio revelou efeitos altamente significativos devido a variedades e apenas significativos para os repetições. A aplicação do látice quadrado a êsses dados proporcionou pouca eficiência, ocasionando correções de pequena monta nas produções, razão pela qual foi considerada apenas a análise estatística como blocos ao acaso. A seguir figuram os quadros da análise do variância. 


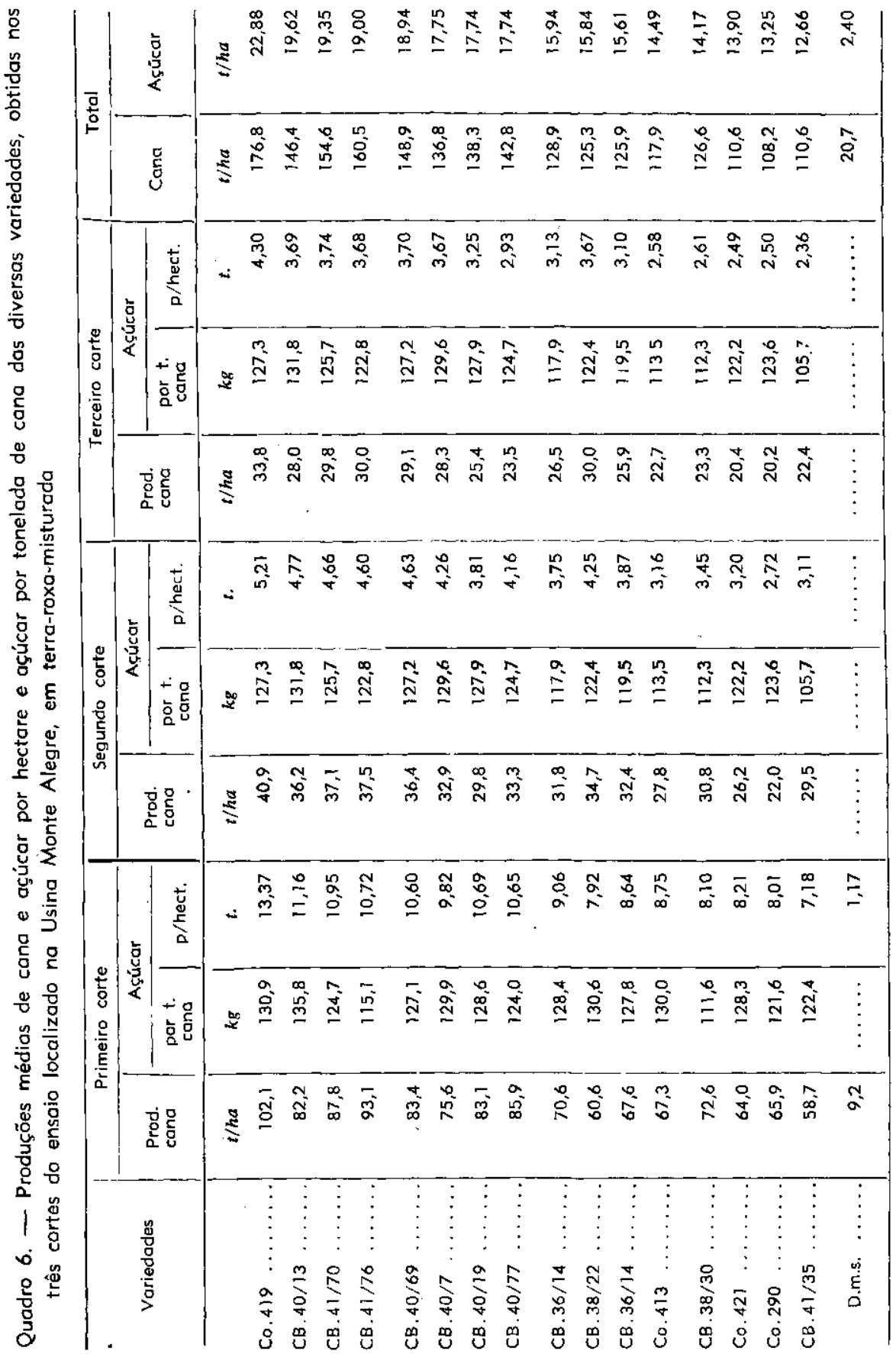


Vor. 17, N.O 4

a) Produção de cana:

\begin{tabular}{|c|c|c|c|c|}
\hline Fontes de variação & G. L. & S. Q. & Q. M. & $\mathbf{F}$ \\
\hline Repetiçōes & 4 & 576,93 & 144,23 & $2,84^{*}$ \\
\hline Variedades & 15 & 11604,57 & 773,64 & 15,21 ** \\
\hline Êrro & 60 & 3052,19 & 50,87 & \\
\hline Total & 79 & 15233,69 & & \\
\hline
\end{tabular}

b) Produção de açúcar:

\begin{tabular}{|c|c|c|c|c|}
\hline Fontes de variaçōo & G. L. & S. Q. & Q. M. & $\mathbf{F}$ \\
\hline 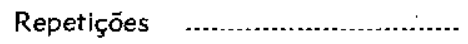 & 4 & 9,0730 & 2,268 & $2,75^{*}$ \\
\hline (n) & 15 & 201,4305 & 13,429 & $16,30 * *$ \\
\hline Êrro & 60 & 49,4313 & 0,824 & \\
\hline Total & 79 & 259,9348 & & \\
\hline
\end{tabular}

Observando os dados de produção dêsse primeiro corte verifica-se que a Co. 419 foi superior a tôdas as variedades em produção de cana e de açúcar, com exceção da CB. 41/76, que se igualou a ela openas em produção de cana. Em seguida, iguais entre si estatisticamente, colocaram-se as variedades CB. 40/13, CB. 41/70, CB. 41/76, CB. $40 / 19$, CB. $40 / 77$ e CB. 40/69. As demais variedades tiveram produção de cana e açúcar inferiores, embora a diferença entre algumas delas e as mencionadas não seja significativa. Como nos ensaios anteriores a CB. 40/13 revelou alto teor de açúcar, dando-se a inverso com a CB. 38/30 que, apesar de o ensaio ter sido cortado em novembro, já no fim da safra, continuou com baixa produção de açúcar por tonelada de cana, excluindo-se assim a possibilidade de ser uma variedade muito tardia e não pobre em açúcar.

No total dos três cortes a aplicação do látice quadrado não proporcionou eficiência alguma, sendo a análise estatística feita como 
blocos ao acaso. A análise da variância revelou efeito altamente significativo devido a variedades e apenas significativo devido a repetições, tanto em produção de cana como de açúcar, conforme se verifica a seguir.

o) Produção de cana:

\begin{tabular}{|c|c|c|c|c|}
\hline Fontes de variação & G. L. & S. Q. & Q. M. & $\mathbf{F}$ \\
\hline (- & 4 & 1826,30 & 456,57 & 1,84 \\
\hline Variedodes & 15 & 26549,38 & 1769,96 & $7,15^{*}$ \\
\hline Êrro & 60 & 14849,26 & 247,49 & \\
\hline Total & 79 & 43224,94 & & \\
\hline
\end{tabular}

D. m. s. $=20,7$

Coef. de variação $=11,7 \%$

b) Produção de açúcar:

\begin{tabular}{|c|c|c|c|c|}
\hline Fontes de variaçāo & G. L. & S. Q. & Q. M. & $\mathrm{F}$ \\
\hline - & 4 & 28,0496 & 7,012 & 2,02 \\
\hline Variedades & 15 & 584,4198 & 38,961 & $11,24^{* *}$ \\
\hline Êrro & 60 & 207,9187 & 3,465 & \\
\hline Total & 79 & $820,388 \mathrm{~T}$ & & \\
\hline
\end{tabular}

D. m. s.. $=2,40$

Coef. de variação $=11,0 \%$

Observando as produções totais dos três cortes verificou-se que a Co. 419 foi superior a tôdas as variedades em produção de açúcar, sendo que em produção de cana igualou-se a ela a CB. 41/76. A seguir, iguais estatisticamente em produção de cana, colocaram-se as variedades CB. $41 / 70, C B .40 / 69, C B .40 / 13, C B .40 / 77, C B$. $40 / 19$ e $C B$. 40/7, sendo as duas últimas inferiores também à $C B$. $41 / 76$. Em produção de açúcar, em seguida à Co. 419, colocaram-se as variedades CB. 40/13, CB. 41/70, CB. 41/76, CB. 40/69, CB. $40 / 7$, CB. 40/19 e CB. 40/77, tôdas elas superiores às demais com 
exceção das $C B .36 / 14$ e $38 / 22$, que se igualaram òs três últimas variedades. A Co. 290 foi a que apresentou menor produção de cana. Em açúcar, embora a CB. 41/35 tenha produzida menos que ela, a diferença entre as duas não foi significativa.

\section{4 - DISCUSSÃO}

Computando-se os dados obtidos nos ensaios realizados verificase que a Co. 290, que era a variedade mais cultivada no Estado de São Paulo há alguns anos e que, atualmente, ainda ocupa apreciável porcentagem de área cultivada com a cana-de-açúcar, teve comportamento pouco satisfatório, pois colocou-se sempre entre as últimas variedades, mostrando-se no entanto superior d̀ $C B .41 / 35$ em quase todos os ensaios e a uma ou outra variedade, em alguns dêles.

As demais variedades tiveram comportamento mais ou menos variável, sendo que mais se destacaram as seguintes: CB. 40/69, CB. 40/13 e CB. $41 / 76$, além da Co. 419.

A CB. 40/69 foi superior à Co. 419 nas usinas Santa Elisa, Tamôio, Santa Bárbara e Itaiquara (nesta última apenas em produção de cana); na usina ltaiquara igualou-se à Co. 419 em produção de açúcar, e em Pôrto Feliz, em produção de cana; foi inferior à mesma variedade na Usina Monte Alegre e apenas em produção de açúcar na Usina Pôrto Feliz.

A CB. 40/13 mostrou-se superior à Co. 419 nas usinas Tamôio, Santa Bárbara e Pôrto Feliz, nesta apenas em produção de açúcar; igualou-se a ela nas usinas Santa Elisa, em produção de açúcar, Pôrto Feliz, em produção de cana e Itaiquara, em cana e açúcar; foi inferior à Co. 410 nas usinas Santa Elisa, em produção de cana, e Monte Alegre, em cana e açúcar.

A CB. 41/76 superou a Co. 419 em Itaiquara e Santa Bárbara, notando-se que nesta última usina foi superior a tôdas as outras variedades, em produção de cana; igualou-se à Co. 419 em Pôrto Feliz e na Usina Monte Alegre, nesta apenas em produção de cana; foi inferior à Co. 419 na Usino Monte Alegre, apenas em produção de açúcar.

A Co. 419 na Usina Santa Bárbara, devido à baixa produção 
apresentada nas socas, foi a variedade com menor produção de cana, e mesmo em produção de açúcar não foi superior estatisticamente a nenhuma outra variedade; na Usina Monte Alegre ela foi superior a tôdas as outras variedades, com exceção da CB. 41/76 que a ela igualou em produção de cana. Os resultados obtidos com a Co. 419 na Usina Santa Bárbara devem ser considerados com restrições, pois estão em desacôrdo com o comportamento normal dessa variedade.

Além das variedades já mencionadas, a CB. 38/22 mostrou-se superior à Co. 419 na Usina Itaiquara, tendo se igualado a ela nas Usinas Santa Elisa, Tamôio e Santa Bárbara; foi inferior à Co. 419 em Pôrto Feliz e na Usina Monte Alegre, sendo que nesta última foi inferior também às variedades CB. 40/13, CB. 41/76, CB. 40/69 e CB. $41 / 70$.

Com relação à riqueza em açúcar, e à precocidade de maturação das variedades, os ensaios não permitiram tirar conclusões definidas. Verificou-se, entretanto, que a CB. 40/13 foi a variedade que apresentou maior riqueza em açúcar; a $C B$. 38/30, por outro lado, sempre mostrou baixo teor de açúcar, abaixo mesmo do que serio admissível. A CB. $40 / 13$ revelou boa riqueza mesmo quando cortada cedo. Sabe-se, aliás, que é ela, entre as variedades estudadas, a de maturação mais precoce. Apesar de suas qualidades de produção e riqueza em açúcar apresenta, porém, o inconveniente de ser das mais suscetíveis ao mosaico.

A CB. 36/14, que tem apresentado bom comportamento no massapê-salmourăo da Usina Itaiquara, sendo uma das variedades preferidas pela administração dessa Usina, nõo confirmou resultados obtidos em ensaio anterior, alí realizado (1).

As variedades Co. 419 e CB. 40/13 são bastante suscetíveis ao mosaico, o que acontece com quase tôdas as variedades do grupo CB. Alcançarão melhores resultados quando para seu plantio forem usadas mudas isentas de moléstias, excluindo a possibilidade de um fracasso como aconteceu com a Co. 419, no ensaio da Usina Santa Bárbara.

Verificou-se em todos os ensaios uma queda de produção muito elevada, do primeiro para o segundo corte; o da Usina Tamôio foi o que apresentou menor queda, cêrca de $40 \%$, atingindo os outros. ensaios 50 e até $60 \%$. 
Para maior facilidade da discussão dos resultados obtidos, são êstes apresentados sob a forma de gráficos. Na figura 1 estão representadas as produções de cana obtidas nos três cortes de cada ensaio, tomando-se como 100 a maior produção de cada ensaio. Fêzse essa transformação para apreciar o comportamento das variedades em um mesmo nível de produção, eliminando-se dêsse modo as naturais variações de produção verificadas nos diversos ensaios.

Verifica-se pela figura 1 que as variedades $C B$. 41/76 e CB. 40/69 foram as de produção mais constantes, a CB. 41/76 tendo produção um pouco inferior apenas na Usina Tamôio. As variedades CB. $40 / 13$ e Co. 419 tiveram produções mais irregulares; como ambas são muito suscetíveis ao mosaico, pode-se atribuir grande parte desta variação ao maior ou menor ataque da moléstia. As maiores produções alcançadas pela CB. 40/13 foram nas usinas onde é melhor o estado sanitário das culturas. Sabe-se que além do mosaico outras moléstias influem no comportamento das variedades, sendo seu efeito agravado pela baixa ou nula ocorrência de chuvas na época em que é feito o corte, o que dificulta sobremaneira a brotação das soqueiras. As variedades CB. 40/19, CB. 38/22, CB. 41/70, CB. $40 / 7$ e CB. $36 / 14$, tiveram também produções pouco variáveis, principalmente a primeira, porém geralmente abaixo das CB. 41/76 e 40/69. A CB. 38/22 apresentou alto produção apenas na Usina Itaiquara, talvez por encontrar nessa usina condições de solo e clima mais compatíveis com suas exigências. As variedades Co. 421 e Co. 413 apresentaram também variações de produção, principalmente a primeira, variação essa que pode ser atribuida em grande parte à conhecida exigência dessas variedades. As outras variedades pouco de interêsse apresentaram a não ser as baixas produções da Co. 290 e da CB. $41 / 35$, notadomente esta. A figura 1 apresenta ainda a média de produção das variedades, o que facilita a apreciação, em conjunto, do comportamento de cada uma em relação às outras.

A figuro 2 apresenta as produções médias de açúcar por tonenalada de cana, que representa com bastante aproximação a riqueza em açúcar de cada variedade.

Verifica-se pela figura 2 que a CB. 40/13 foi a variedade que apresentou maior riqueza em açúcar $(127,9 \mathrm{~kg}$ por tonelada de cana) sobressaindo-se em relação às demais. $A$ CB. $38 / 30$ produziu apenas 
Segalla \& Alvarez

Nov., 1958 Variedades DE CANA-DE-AÇÚCAR. II.

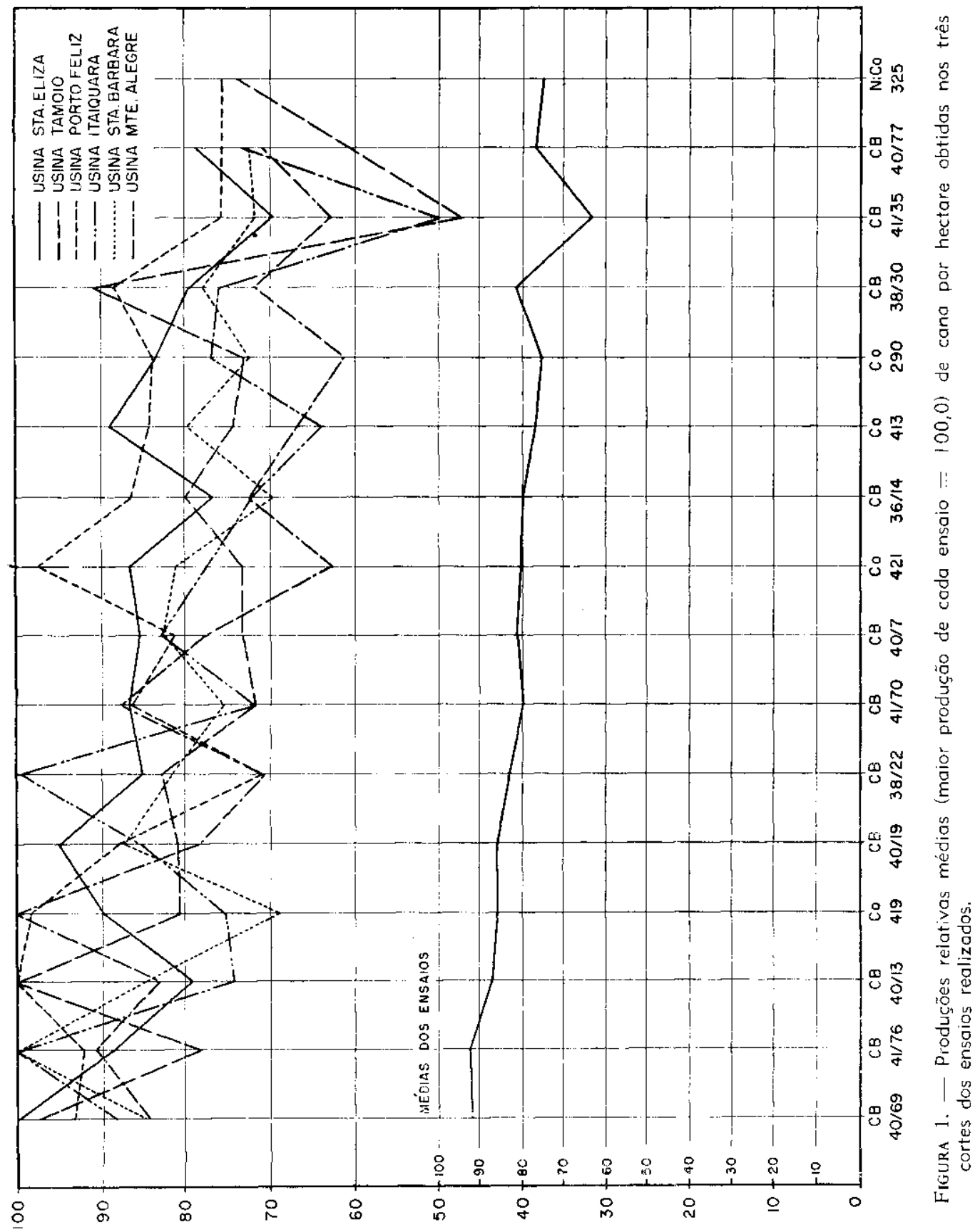


$108,3 \mathrm{~kg}$ de açúcar, bem abaixo de tôdas as outras. A CB. 41/76 também apresentou baixa produção de açúcar. Deve-se, porém, ressaltar que, tanto ela como as variedades CB. 36/14, CB. 38/22 e Co. 421 são de maturação mais tardia e, como a maior parte dos ensaios foi cortada em agôsto, ficaram essas variedades prejudicadas na produção de açúcar, uma vez que não tinham ainda completada sua maturação.

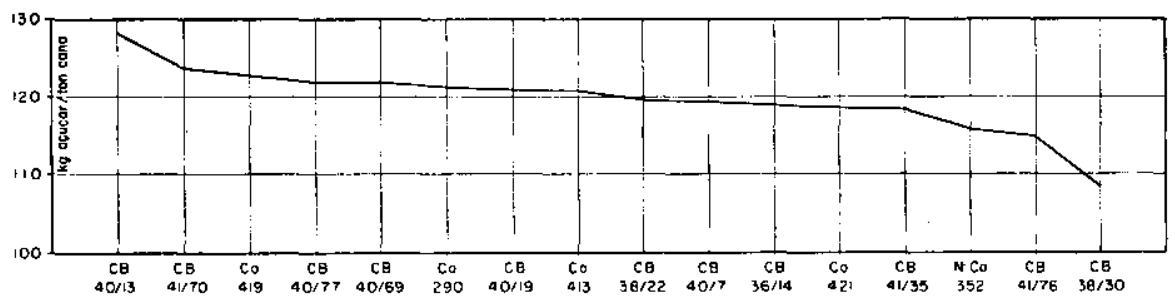

Figura 2. - Prcduções de açúcar por tonelada de cana (médias de todos os ensaios) das variedades estudadas.

Na figura 3 são apresentadas as produçōes de açúcar, obtidas nos três cortes dos ensaios, a maior produção obtida em cada ensaio sendo igual a 100 .

Algumas variedades tiveram produções muito varióveis, conseqüência das produções de cana. Confrontando-se as médias apresentadas nas figuras 1 e 3 verifica-se que a CB. 40/13 teve melhor produção em açúcar (relativamente à produção de cana); um pouco menos produziu a CB. 41/76, e bastante a CB. 38/30. Também a CB. 41/70 apresentou melhor produção em açúcar (relativamente à produção de cana).

Independentemente da análise estatística, pelo comportamento apresentado nos ensaios poder-se-iam classificar as variedades do seguinte modo: a) melhores - CB. 40/69, CB. 40.13 e CB. 41/76; b) boos - Co. 419, CB. $40 / 19$ e, um pouco abaixo. CB. 38/22, CB. $41 / 70$ e $C B .40 / 7$ (estas três com algumas restrições, pois houve ensaios em que se comportaram mal); c) regulares - CB. 40/77, CB. 36/14. Co. 413 , Co. 290 e Co. 421; d) fracas - N:Co. 352, CB. $38 / 30$ e CB. $41 / 35$. 
Segalla \& Alvarez

Nov., 1958 VARIEDAdes De CANA-DE-AçÚCAR. II.

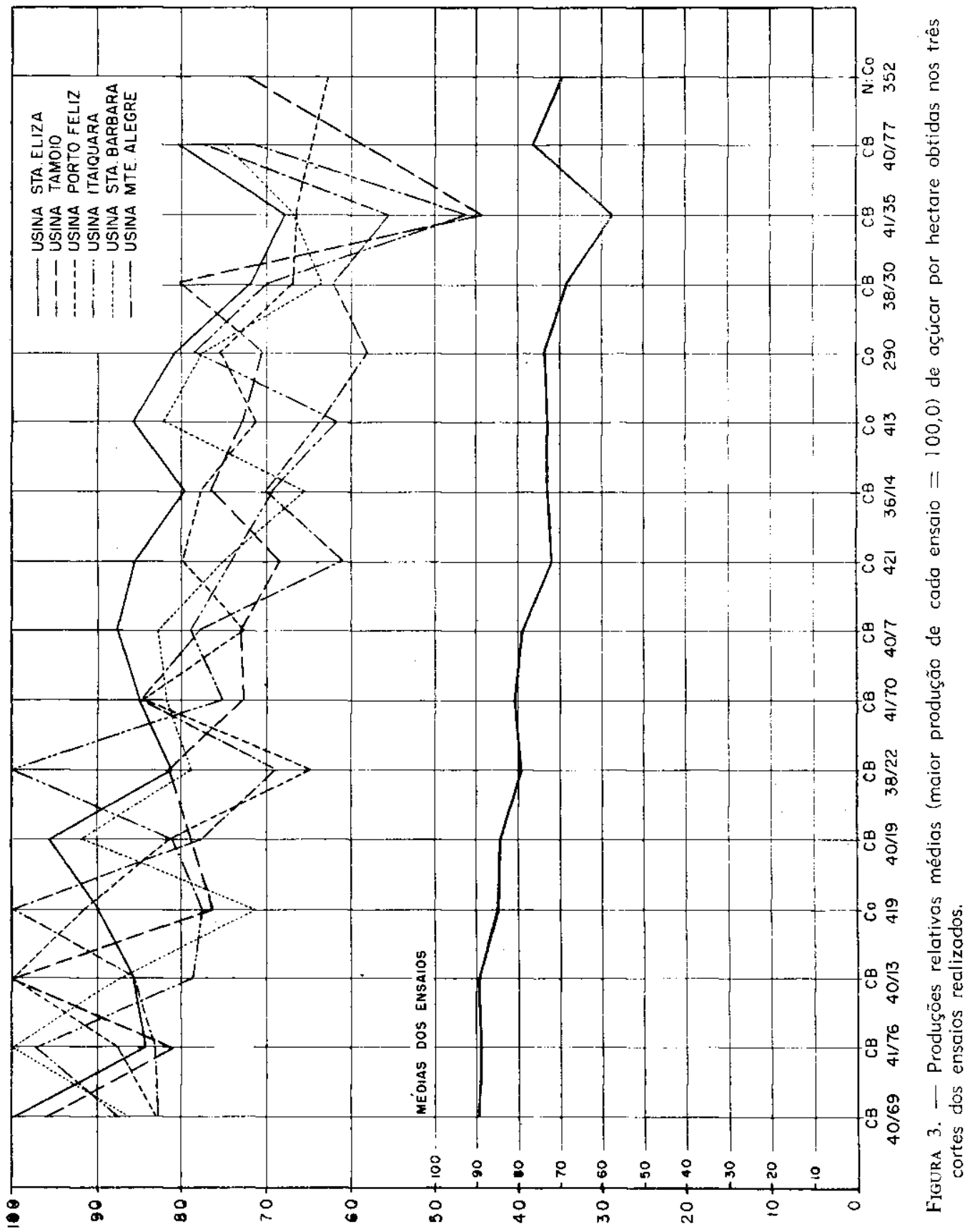




\section{5 - CONCLUSÕES}

Com base nos resultados obtidos nesta série de ensaios podem-se tirar as seguintes conclusões.

a) A Co. 290 , pelas baixas produções apresentadas, não mais deve ser cultivada, pois outras variedades existem que a substituem com vantagem.

b) As variedades CB. $40 / 69$, CB. $41 / 76$ e Co. 419 são as mais recomendóveis pará qualquer tipo de solo, em qualquer região do Estado de São Paulo.

c) A CB. 40/13, apesar das boas produções apresentadas e de ter sido a variedade que revelou maior riqueza em açúcar e também maior precocidade de maturação, só pode ser cultivada com cuidados especiais. Dada a sua alta suscetibilidade ao mosaico exige, bem como a Co. 419, o emprêgo de mudas sãs, isentas de moléstias. Usinas ou lavradores que nōo organizem viveiros para produção de mudas selecionadas não devem plantá-la, pois, provòvelmente dentro de poucos anos estará totalmente degenerada em consequiência da moléstia.

d) Além das variedades mencionadas, outras se destacaram e podem também ser cultivadas, em solo e clima semelhantes àqueles em que se realizaram os ensaios. São as seguintes: CB. 40/19, nas usinas Santa Elisa, Itaiquara e Santa Bárbara; sendo que nas outras usinas teve ela comportamento satisfatório, podendo também ser cultivada; CB. 38/22, nas usinas Tamôio e Itaiquara; nesta última usina, mostrou-se, juntamente com a CB. 41/76 como a melhor variedade; CB. 4I/70 nas usinas Pôrto Feliz e Monte Alegre.

e) Pelos resultados apresentados podem ser cultivadas, porém com expectativa de produções inferiores, as seguintes outras variedades: na Usina Santa Elisa, CB. 40/7, Co. 413, Co. 421, CB. 41/70, CB. 38/22; na Usina Tamôio, CB. 36/14; na Usina Santa Bárbara, CB. 40/7, Co. 413 e CB. 41/70; na Usina Monte Alegre, CB. 40/7 e CB. $40 / 77$.

c) As variedades $\mathrm{N}:$ Co. 352 e CB. $41 / 35$, pelas baixas produções apresentadas, não devem ser cultivadas no Estado de São Paulo, assim como a CB. 38/30 que, embora na Usina Tamôio tenha apresentado produção de cona superior à da Co. 419, não se recomenda nem mesmo para esta usina, devido à baixa riquezo em açúcor que apresenta. 


\section{SUGAR CANE VARIETY TRIALS 1953-1956}

\section{SUMMARY}

A new series of six sugar cane variety trials was carried out from 1953 to 1956, at the following localities in the State of São Paulo: 1) "Usina Santa Elisa", Sertãozinho, and 2) "Usina Tamôio", Araraquara, both on "terra-roxa-misturada" soil type; 3) "Usino Pôrto Feliz", Pôrto Feliz, on the "terra-roxa-misturada" glacial soil; 4) "Usina Itaiquara", Tapiratiba, on the "massapê-salmourão" soil; 5) "Usina Santa Bárbora", Santa Bárbaro Do Oeste, on glacial sandy soil, and 6) "Usina Monte Alegre", Piracicaba, on the "terra-roxa-misturada" soil.

Four by four lattice squares with 5 replications were used in all locations. The varieties tested were the following: Co.290, Co.413, Co.419, Co.421, CB.36/14,

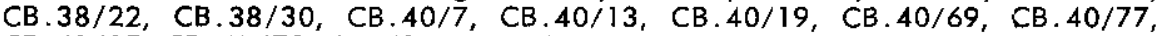
CB.4l/35, CB.4l/70, CB.4l/76 and N:Co.352.

Three harvests (plant cane and two stubbles) were done in each of the six tests. Statistical onalysis was made of cane and sugar yields of the first harvest os well as of the sum of the three harvests.

The results allowed the following conclusions:

a) becouse of its small yield, the variety Co.290 is not recommended for plantation;

b) the varieties $C B .40 / 69, C B .41 / 76$ and $C 0.419$ are the best to be planted all over the State of São Paulo.

c) the variety CB. 40/13, in spite of its big yield and high sugar content should not be planted, unless mosaic-free cuttings are availoble;

d) the following good yielding varieties con be planted in regions similar to those in which the testes were carried out:

CB. 40/19 ("Usino Tamôio", "Usina Itaiquaro", and "Usino Sonto Bárbara");

$\mathrm{CB} .38 / 22$ ("Usina Tamôio", and "Usina Itaiquara"; in the latter region this voriety and $\mathrm{CB} .41 / 76$ were the best);

CB.41/70 ("Usina Pôrto Feliz" and "Usina Monte Alegre");

e) the following vorieties in spite of being low yielders can be planted in regions similar to those in which the fields trials were conducted: $C B .40 / 7, C 0.413$, Co. 421, CB.41/70 and CB.38/22 ("Usina Sonto Elisa"); CB.40/7, Co.413 and CB.41/70 ("Usina Santa Bárbara"); CB.36/14 ("Usina Tamôio"); and CB.40/7 and CB.40/77 ("Usina Monte Alegre");

f) the following varieties are not recommended for the State of São Paulo: $N: C o .352, C B .41 / 35$ and $C B .38 / 30$, the latter for its low sugor content.

\section{LITERATURA CITADA}

1. ARCENEAUX, G. A. Simplified method of theoretical sugar yield calculations. Int. Sug. J. 38:264-265. 1935.

2. SEGALLA, A. L. \& ALVAREZ, R. Ensaios de variedodes de cana de açúcar. I - série de ensoios realizados de 1951 a 1954. Bragantia 15:[373]-392. 1956.

3. - Comportamento de variedades de cana-de-açúcar no arenito de Bauru. Bragantia 16:[35]-43. 1957. 